\title{
Atualidade de Roland Freisler
}

Nilo Batista ${ }^{1}$

\begin{abstract}
Resumo
O artigo analisa a concepção de direito penal de Roland Freisler, segundo secretário-geral do Ministério da Justiça, e presidente do Tribunal do Povo (Volksgerichthof), criado na Alemanha em 1934, especialmente para o julgamento de crimes políticos contra o regime nazista. $O$ artigo de Freisler é tomado como um posicionamento dogmático ou como um manifesto político criminal, onde Freisler pretendia estabelecer um "conceito geral de empreendimento". O conceito de "empreendimento" (Unternehmung) se originara da alta traição e sua disciplina se expandiu para alguns outros delitos. A concepção de direito penal em Freisler realiza a superposição entre direito e moral.
\end{abstract}

Palavras-chave: Direito penal nazista; Subjetivismo nazista; Roland Freisler.

\section{Roland Freisler en la actualidad}

\section{Resumen}

El artículo analiza la concepción de derecho penal de Roland Freisler, segundo secretario general del Ministerio de Justicia, y presidente del Tribunal del Pueblo (Volksgerichthof), creado en Alemania en 1934 para juzgar en particular los crímenes políticos contra el régimen nazi. El artículo de Freisler es tomado como un posicionamiento dogmático o como un manifiesto político criminal, donde Freisler pretendía establecer un "concepto general de Emprendimiento". El concepto general de "emprendimiento" (Unternehmung) se originaba en la alta traición y su aplicación se expandió hacia algunos otros delitos. La concepción de derecho penal de Freisler realiza la superposición entre derecho y moral.

Palabras clave: Derecho penal nazi; subjetivismo nazi; Roland Freisler.

\section{Roland Freisler in Today's World}

\section{Abstract}

This article analyzes the concept of criminal law according to Roland Fresiler, second state secretary of the Reich Ministry of Justice and president of the Volksgerichthof [People's Court] created in Germany in 1934, especially in terms of the judgment of political crimes against the Nazi regime. Freisler's article is taken as a dogmatic position or a criminal political manifesto, in which he aims to establish a "general concept of political offense". The concept of "offense" (Unternehmung) originated with high treason and the field was expanded to encompass other crimes. Freisler's concept of criminal law entails an overlapping of law and ethics.

Keywords: Nazi criminal law; Nazi subjectivism; Roland Freisler.

\footnotetext{
${ }^{1}$ Professor Titular do Programa de Pós-Graduação em Direito da Faculdade de Direito do Estado do Rio de Janeiro. E-mail: nilobatista@nb-advs.com.br
} 


\section{Actualité de Roland Freisler}

RésuméCet article analyse la conception du droit pénal de Roland Freisler, secrétaire d'État au ministère de la Justice, puis président du Tribunal du peuple (Volksgerichthof), créé en 1934 en Allemagne pour juger les crimes politiques contre le régime nazi. L'article de Freisler est ici considéré comme un positionnement dogmatique, comme un manifeste politique criminel où Freisler entend établir un " concept général de l'entreprise ». Le concept d'« entreprise » (Unternehmung), qui désignait la haute trahison, sera étendu à d'autres délits. La conception du droit pénal chez Freisler procède d'une superposition du droit et de la morale.

Mots-clés : Droit pénal nazi ; subjectivisme nazi ; Roland Freisler.

\section{罗兰弗雷斯勒的目前情况}

\section{摘要:}

本论文分析德国司法部次长，德国人民法院院长(Volksgerichthof) 罗兰弗雷斯勒(Roland Freisler)

的一些刑法概念, 这个人民法院是1934年成立的, 主要是审判那些反纳粹的政治犯。弗雷斯勒条例既是一个

法律条文, 又是一个关于政治犯罪的宣言, 弗雷斯勒尝试建立政治犯罪的总概念, 所指的是高级叛变, 已及 由此连带的其他违法行为。在弗雷斯勒的刑法概念里, 法律和道德糅合在一起。

关键词: 纳粹刑法, 纳粹主义的主体性, 罗兰弗雷斯勒

Quando recebi de Raúl Zaffaroni a incumbência de redigir umas notas sobre um artigo no qual Roland Freisler (1893-1945) concebia a tentativa aos moldes do direito penal nazista, a primeira coisa que me ocorreu foi perguntar-me: por que Raúl não se dirigiu a Francisco Muñoz Conde? Afinal de contas, o catedrático de Sevilha tem experiência específica no setor, adquirida quando corajosa e argutamente desvelara as predileções políticas de Edmundo Mezger.

Logo percebi meu equívoco, e para ilustrá-lo recorro ao personagem de Machado de Assis que, tendo resolvido escrever suas memórias após o próprio óbito, explicava ao leitor não ser "propriamente um autor defunto, mas um defunto autor"². Aí está toda a diferença: Mezger foi um jurista nazista enquanto Freisler foi um nazista jurista. A despeito das sombras que a suástica deixou em sua produção (como a engenhosa contribuição para a culpabilidade de autor), o nível da dogmática mezgeriana é reconhecidamente

\footnotetext{
${ }^{2}$ Assis, Machado de (1979). Memórias Póstumas de Brás Cubas, Rio de Janeiro: Nova Aguilar, cap. I, v. 1, p. 511-640.
} 
elevado. Já Freisler foi, na abalizada opinião de William Shirer, "talvez o mais sinistro e sanguinário nazista no Terceiro Reich, depois de Heydrich"3.I

O artigo sobre tentativa foi escrito por Freisler quando ele ocupava o cargo de segundo secretário-geral do Ministério da Justiça, do qual seria catapultado para a presidência do famigerado Tribunal do Povo (Volksgerichthof), criado em 1934, especialmente para o julgamento de crimes políticos. Narra lan Kershaw ${ }^{4}$ que Hitler ficara muito irritado com a pena "branda" (cinco anos de prisão) aplicada a um certo Ewald Schlitt, que agredira e matara sua esposa num manicômio, insistindo com o ministro da Justiça para que interviesse no assunto. Como este último procrastinasse sua intervenção, seja pelos empecilhos legais seja na esperança de que o Führer esquecesse o assunto, Freisler foi acionado, e poucos dias depois a primeira sentença estava anulada e uma segunda levou Schlitt à guilhotina.

Mas foi na presidência do Tribunal Popular que Freisler esforçou-se por merecer o epíteto de sanguinário. Entre os casos mais emblemáticos destacam-se dois. $\mathrm{Na}$ Universidade de Munique alguns estudantes e um professor ousaram, em fevereiro de 1943, distribuir um manifesto criticando a morte de centenas de milhares de soldados alemães em Stalingrado. Denunciados por um bedel, presos e torturados, seriam julgados em quatro dias pelo Tribunal do Povo; a estudante Sophie Scholl, que na tortura teve uma perna fraturada, foi guilhotinada, como seu irmão Hans e outro colega, na mesma tarde do último dia do julgamento.

Mas onde o paroxismo punitivo de Freisler explodiu grotescamente foi no julgamento dos remanescentes da conspiração e do frustrado atentado contra Hitler em 20 de julho de 1944. O Führer ordenara que todos deveriam ser enforcados (e não fuzilados ou mesmo guilhotinados), a despeito da primeira leva de oito acusados incluir um marechal, três generais, três oficiais e um conde. Num assomo preventivista-geral, Goebbels determinara fosse o julgamento filmado para exibição às tropas (em linguagem de hoje, para reafirmar a vigência da norma e estabilizar decepções); apreendido, tal filme seria exibido em Nuremberg, tendo entre os espectadores William Shirer. Freisler reprovava e insultava os acusados: "velho sujo" foi como se dirigiu ao marechal, a quem a

\footnotetext{
${ }^{3}$ Shirer, William L. (1967). Ascensão e Queda do III Reich, trad. L. G. Carvalho, Rio de Janeiro: Civilização Brasileira, v. IV, p. 130-200, p.130.

${ }^{4}$ Kershaw, lan (2010). Hitler, trad. P. M. Soares, São Paulo: Cia das Letras, p. 742, 776 e 883.
} 
Gestapo subtraíra a dentadura e fornecera roupas imundas e largas; "patifes", "traidores", "covardes" e "assassinos" foram outros prosônimos de que se valeu largamente. Parece que até alguns dos advogados dativos aderiram à acusação, tendo um deles admitido que seu defendente era mesmo um criminoso e merecia o pior castigo. A execução foi cruel, sendo os padecentes içados por arames presos em ganchos numa trave chumbada ao teto da sala, como num açougue. Parece que também a execução foi filmada, porém não se descobriu jamais a película.

No dia 03 de fevereiro de 1945, envergando sua toga vermelha, sentado à frente de um busto de Hitler, Roland Freisler presidia uma sessão do Tribunal do Povo quando uma bomba caiu em plenário, encerrando a carreira do nazista jurista. O acusado daquela sessão, Schlabrendorff, sobreviveria ao tribunal e à bomba, porém só sobreviveu ao primeiro por causa da segunda. Poucos meses depois, o Exército Vermelho entraria em Berlim.

Podemos ler o artigo de Freisler como um posicionamento dogmático ou como um manifesto político criminal, porém, embora ambas as perspectivas se condicionem e se realimentem teoricamente, o exame individualizado de cada uma delas parece mais proveitoso.

Conhecemos a longa tradição alemã, doutrinária e jurisprudencial, de uma fundamentação subjetivista da punibilidade da tentativa, tradição que se exprimiria no pós-finalismo particularmente no subjetivismo monista e em certas versões do funcionalismo. Quais as especificidades do tosco subjetivismo nazista?

Freisler pretendia estabelecer um "conceito geral de empreendimento" que, no "direito penal do futuro", substituiria o conceito de ação e tornaria "a distinção entre tentativa e consumação sem importância". O conceito de "empreendimento" (Unternehmung) se originara da alta traição (um delito que, se consumado, estaria impune - já que o traidor da véspera teria hoje o poder punitivo em suas mãos) e sua disciplina se expandiu para alguns outros delitos. Estava o "empreendimento" definido no $§ 11,6$ do código de 1871, laconicamente: "empreender um fato: sua tentativa e sua consumação (Unternehmen einer Tat: derem Versuch und deren Vollendung)". Nos delitos de empreendimento, portanto, a equivalência entre tentativa e consumação impediria qualquer mitigação obrigatória da pena quando o resultado se frustrasse. Muitas críticas 
se levantariam contra esta criação legal, que os projetos de reforma durante a república de Weimar haviam pretendido suprimir.

O projeto de código penal nazista de 1936, com o dedo de Freisler (citado na nota de rodapé $n$ ํ 11 , referente ao dispositivo sobre empreendimento) procurou "aperfeiçoar" o conceito com a seguinte regra: "§ 8: Empreende um fato punível quem o inicia (wer sie beginnt)". O que seja "iniciar" um crime - afinal, a complexa indagação da teoria da tentativa - vinha esclarecido numa fórmula assustadora, também com Freisler citado no rodapé (nota 10): “§ $7^{\circ}$ - [...] Início do fato é qualquer ação que, ainda que apenas segundo a representação do autor sobre os fatos (wenn auch nur nach der Vorstellung des Täters vom Sachverhalt) se dirija imediatamente à realização do tipo". Com sabor de interpretação autêntica, Freisler conclui que "apenas começado o feito, o direito penal deve opor a seu autor a severidade de todas as suas cominações penais”. Já veremos as consequências dessa opinião para a tentativa inidônea.

Coerentemente com as linhas básicas do Willenstrafrecht, para Freisler "o decisivo para a intervenção penal do Estado é a vontade criminal ou a disposição para o fato do autor, e não o resultado provocado por ação dessa vontade". Não pode espantar que, para ele, o iter criminis tenha seu começo lá longe, no nebuloso manancial da vontade: na "tentação". Conectar o desejo - antes mesmo de qualquer decisão do sujeito sobre os meios de realizá-lo - a um injusto é algo pré-moderno, que remete ao direito penitencial canônico.

A punibilidade da tentativa inidônea constitui, a partir de tais premissas, consequência inevitável. Depois que "o autor [...] começa a execução de um fato punível" - explicava Freisler a seus colegas - "passa a ser um inimigo da ordem pacífica popular", e a lei tem que intervir. Nesta passagem, ele agradece ao Reichsgericht ter mantido, a despeito da crítica doutrinária, o arraigado subjetivismo que em 1880 havia levado à condenação uma tentativa de abortamento com meios absolutamente inadequados, e mais tarde chegaria a castigar a tentativa de homicídio exercida sobre um cadáver.

$\mathrm{Na}$ tentativa supersticiosa, na qual "a inutilidade dos meios alcança o limite do ridículo", como "o povo reconhecerá que o meio empregado não pode conduzir ao objetivo proposto por efeito de uma lei da natureza", em princípio "apenas cabe o sorriso 
complacente". Este sorriso - que Freisler talvez tenha extraído de Hellmuth von Weber ${ }^{5}-$ não perduraria, contudo, se perante "a magnitude da intensidade da vontade do autor fosse imaginável, com alta probabilidade, que verificada a inutilidade do meio empregado (o autor se premuniria) de outro idôneo". Ou seja, se o juiz, perante aquela mulher que zelosamente "tentou" matar o marido sacrificando à divindade um animal e outras oferendas, puder profetizar que mais dia menos dia ela recorrerá à faca de cozinha, deverá condená-la por tentativa de homicídio qualificado; e como empreende um fato punível quem o inicia, sendo decisivo para caracterizar o início a representação do autor sobre os fatos, ela sofreria afinal as penas do homicídio qualificado consumado.

Quanto ao delito imaginário, Freisler o tem por impunível, e podemos arriscar a afirmação de ser esta a única unanimidade doutrinária em sede de tentativa: nem os nazistas conseguiram fundamentar sua punibilidade.

Os efeitos do arrependimento são remetidos "ao âmbito da quantificação penal", interessando como "estado de ânimo", como "signo da menor permanência da vontade criminal" que só excepcionalmente eximiria de pena quem "se houvesse esforçado com suas maiores potências" para evitar o resultado; mas tanto a mitigação quanto a isenção de pena constituiriam faculdade que o juiz poderia ou não exercer, de olho na alma do acusado, em busca mais de um remorso sincero do que de um arrependimento eficaz.

Por fim, chama a atenção que, tratando da individualização da pena, Freisler invoque o magistério de seu companheiro Dahm no sentido de que "a decisão quantificadora da pena deve ser um juízo adequado à personalidade que 0 autor tenha manifestado". A lei penal brasileira arrola a "personalidade do agente" entre os elementos que deve o juiz consultar para estabelecer a pena-base, primeira etapa do procedimento de individualização judicial. Isto, porém, tem sido uma fonte inesgotável de arbitrariedades, voluntarismos e preconceitos, pois, como a mais avançada doutrina expõe, existe no elemento personalidade "ausência de precisão conceitual e carência de uma metodologia de análise" (Salo de Carvalho), tratando-se de "um conceito fluídico, não tendo o aplicador sequer habilitação técnica para proferir juízo de natureza antropológica, médica, psicológica ou psiquiátrica" (Rodrigo Duque Estrada Roig). Para o direito penal da vontade, no entanto, uma culpabilidade de autor é quase um corolário inevitável.

\footnotetext{
${ }^{5}$ Weber, Hellmuth von (2008). Lineamientos del Derecho Penal Aleman, trad. L. G. Brond, B. Aires: Ediar, p. 85.
} 


\section{Passagens. Revista Internacional de História Política e Cultura Jurídica}

Rio de Janeiro: vol. 7, n⿳…, janeiro-abril, 2015, p. 5-14.

Se o direito penal da vontade foi uma espécie de caricatura dos inúmeros subjetivismos "respeitáveis" que o antecederam e o sucederam, a política criminal propugnada por Freisler repercute preocupantemente em formulações recentes e contemporâneas. É como se, a despeito da derrota do nazismo como projeto político, muitas de suas idéias houvessem sobrevivido e mesmo, a exemplo de tantos de seus partidários, emigrado clandestinamente para outras paragens, inclusive para o continente americano. Examinemos algumas das concepções que Roland Freisler expôs em seu artigo.

Para ele, o legislador penal tem que fazer uma escolha: ou ele responde "ao injusto ocorrido [...] em forma de dano", ou ele cria "um aparato continuamente operativo de autolimpeza" do corpo social. Aí se coloca, com claridade, a opção entre um direito penal do fato e um direito penal de autor. A "meta" do direito penal nazista não se detém, portanto, em "aniquilar o efetivo perturbador da paz" (o autor de um crime), mas ambiciona também aniquilar "o próprio tipo do perturbador da paz", identificado como "inimigo" (tanto quanto sua vontade é também uma "vontade inimiga"). Aliás, talvez para revelar a profundidade de seu subjetivismo, Freisler não deixa de registrar que "inimigo da ordem popular é, antes de tudo, quem cai em tentação". Paz e inimigo - palavras que sugerem universos semânticos bem distintos - repetem-se e mesclam-se compulsivamente no texto de Freisler. A metáfora do "agricultor previdente", utilizada por Inocêncio VIII em 1484 para legitimar as atividades de Kramer e Sprenger ${ }^{6}$ e presente em tantos outros documentos inquisitoriais, é empregada com desenvoltura: o "direito do futuro" deve "extirpar o mal pela raiz", deve empreender a "erradicação de todas as forças anárquicas", compreendendo que "o inimigo contra o qual luta o jardineiro está na raiz das ervas daninhas". Todos os perigos que a noção de "pureza" introduz, como desde Mary Douglas é fácil perceber, dinamizados por uma formidável concentração de poder punitivo, desaguarão aqui num chocante genocídio.

Olhemos por um instante para hoje. O sistema penal adota o discurso bélico: ao lado da "guerra contra as drogas", uma sucessão de "combates", de "lutas contra". Isso contamina outros setores: também na saúde se recorre ao "combate contra a dengue", e o mosquito que a transmite é chamado de "inimigo". Os partidários do direito penal do

\footnotetext{
${ }^{6}$ Kramer, Heinrich; Sprenger, James (1991). O Martelo das Feiticeiras, trad. P. Fróes, Rio de Janeiro: Rosa dos Ventos, p. 43-46.
} 
inimigo olham para o outro lado, como se a evidente afinidade com o léxico nazista não pudesse perturbá-los: eles gostam de dialogar com Hobbes, mas fingem ignorar Freisler. No Rio, a palavra "paz" está sendo inexoravelmente desmoralizada pelo programa das Unidades de Polícia Pacificadora, que compartilha algumas características com o modelo do "campo", que tanto deve ao nazismo, e tem origem no controle da peste, como se observa na descrição de Foucault: "Trata-se nesses regulamentos relativos à peste de quadrilhar literalmente as regiões, as cidades no interior das quais existe a peste, com uma regulamentação indicando às pessoas quando podem sair, como, a que horas, o que devem fazer em casa, que tipo de alimentação devem ter, proibindo-Ihes este ou aquele tipo de contacto, obrigando-as a se apresentar a inspetores, a abrir a casa aos inspetores". Uma UPP é exatamente isto, com a diferença de que ao invés de abrirem suas casas à inspeção os moradores têm seus lares invadidos pela polícia, autorizada por um mandado de busca domiciliar genérico que não tem qualquer fundamento legal. Estado de exceção em pílulas: o que diria Carl Schmitt dessa soberania judicial?

Voltemos ao artigo de Freisler. Embora muito claro seu compromisso preventivogeral - a lei "deve exercer um saudável efeito [...] sobre as pulsões que predispõem o povo ao injusto" - ele não dispensa o retribucionismo: afinal, "a culpabilidade exige expiação" e "a exigência de expiação é vital para nós" (os nazistas). O funesto resultado é uma teoria combinatória, na qual só não haverá punição quando esta "não for requerida nem para expiação, nem por razões de segurança". A teoria combinatória, que aliás está inscrita no artigo 59 in fine do código penal brasileiro, converte a aplicação da pena num jogo parecido com aquele do lobo e do cordeiro: faltando a necessidade preventiva, sempre subsistirá alguma exigência retributiva; despicienda no caso a prevenção geral, sempre restará algo para o reset social do condenado. A única coisa certa é a pena.

Outro ponto que chama a atenção é a superposição entre direito e moral. Como a "tentação" é o ponto de partida do interesse penalístico, o direito tem que ter "como fundamento a ordem ética", tem que "estar enraizado na moral popular". Freisler transcreve duas passagens das "Diretrizes Nazistas para um novo direito penal alemão" bem significativas: este novo direito "deve ser direito popular, originado da vontade do povo e extraído de sua alma"; "para o pensamento alemão há coincidência entre valoração ética, sentimento do dever e sentimento jurídico". É possível que livros de 


\section{Passagens. Revista Internacional de História Política e Cultura Jurídica}

Rio de Janeiro: vol. 7, n⿳…, janeiro-abril, 2015, p. 5-14.

Fichte tenham sido lançados às fogueiras que consumiram literatura, arte e filosofia "degeneradas".

Mencionemos um dos trechos em que a atualidade do Roland Freisler é ainda mais evidente: a lei penal não pode "esperar até que se produza a violação da ordem jurídica, ou seja, até que a execução tenha obtido êxito"; ao contrário, "exige-se uma intervenção jurídico-penal contra a preparação criminal". Aqui os defensores dos delitos-obstáculo, do perigo abstrato, da criminalização de atos preparatórios e todas os demais expedientes que se poderiam reunir sob a rubrica de "antecipação da tutela" encontrariam muita afinidade; aqui os velocistas do direito penal constatariam como a velocidade embriaga e mata. A flexibilização de tipos legais é também sustentada por Freisler, bem como a aplicação analógica da lei, esta última já então vigente.

Por fim, a categoria da "fidelidade" vinculava o cidadão ao ordenamento jurídico, e convertia todo delito numa espécie de traição, de infidelidade. (Relembre-se que, como Larenz deixou muito claro, "sujeito de direito só é quem for membro da comunidade do povo, e só é membro da comunidade do povo quem tem sangue alemão".) Mas se existe no crime a quebra de um dever de fidelidade, então todo crime - como advertirá uma das Diretrizes - "é basicamente desonrante, afeta a honra indivisível do homem". E eis como um velho atributo da pena, a infamação, obtém na primeira metade do século XX uma improvável ressurreição e, mesmo após a derrota política do projeto que a ressuscitara, uma sobrevida não apenas no senso comum, mas também em alguns redutos doutrinários e forenses. O juiz que insulta o réu que condenou é um prosélito de Roland Freisler, saiba-o ou não.

As inúmeras afinidades acima observadas entre a política criminal nazista e diversas propostas político-criminais contemporâneas deviam inquietar-nos. Há umas similitudes preocupantes. A pena constitui um a priori indescartável, e sua fundamentação compraz-se na petição de princípio: temos que punir porque, caso contrário, não puniríamos. A criação publicitária do estereótipo do inimigo é o passo prévio: lá, "judeus" e "comunistas", aqui "traficantes" e "corruptos". O mesmo desprezo pelos princípios do velho e bom direito penal liberal. Na sucessão de crises, uma única economia floresce, alheia ao turbilhão dos mercados, a maior empregadora, a indústria do controle do crime. Juízes moralistas. Polícia por todos os poros. Judicialização do cotidiano. Criminalização das manifestações. Para onde estamos indo? 


\section{Referências}

Assis, Machado de (1979). Memórias Póstumas de Braz Cubas, Rio de Janeiro: Nova Aguilar, cap. I, v. 1.

Carvalho, Salo de (2013). Penas e Medidas de Segurança no Direito Penal Brasileiro, São Paulo: Saraiva.

Douglas, Mary (s.d.). Pureza e Perigo, Trad. S. P. Silva, Lisboa: Ed. 70.

Foucault, Michel (2008). Segurança, Território, População, trad. E. Brandão, São Paulo: Martins Fontes.

Fragoso, Christiano; Fragoso, Rodrigo Falk (2014). "Código criminal e código criminoso: subsídios e notas ao código penal nazista de 1936". In Fernandes, Marcia Adriana; Pedrinha, Roberta Duboc (Org.) (2014). Escritos Transdisciplinares de Criminologia, Direito e Processo Penal, Rio de Janeiro: Revan, p. 211 ss.

Kershaw, Ian (2010). Hitler, trad. P. M. Soares, São Paulo: Companhia das Letras.

Kramer, Heinrich; Sprenger, James (1991). O Martelo das Feiticeiras, trad. P. Fróes, Rio de Janeiro: Rosa dos Ventos.

Muñoz Conde, Francisco (2005). Edmund Mezger e o Direito Penal de seu Tempo, trad. P. C. Busato, Rio de Janeiro: Lumen luris.

Roig, Rodrigo Duque Estrada (2013). Aplicação da Pena, São Paulo: Saraiva.

Shirer, William L. (1967). Ascensão e Queda do III Reich, trad. L. G. Carvalho, Rio de Janeiro: Civilização Brasileira, v. IV.

Vormbaum, Thomas; Rentrop, Kathrin (Org.) (2008). Reform des Strafgesetzbuchs, Berlim: Berliner Wissenschafts.

Weber, Hellmuth von (2008). Lineamientos del Derecho Penal Aleman, trad. L. G. Brond, B. Aires: Ed. Ediar. 